\title{
Haemophilia protects against ischaemic heart disease: a study of risk factors
}

\author{
F. R. RosendaAl, ${ }^{1}$ E. Briët, ${ }^{2}$ J. Stibbe, ${ }^{3}$ G. van Herpen, ${ }^{4}$ J. A. Gevers Leuven, ${ }^{5}$ A. Hofman ${ }^{6}$ And \\ J. P. VANDENBRouckE ${ }^{1}{ }^{1}$ Department of Clinical Epidemiology. University Hospital Leiden, \\ ${ }^{2}$ Department of Haematology, University Hospital Leiden, ${ }^{3}$ Department of Haematology, University Hospital Rotterdam, \\ ${ }^{4}$ Department of Cardiology, University Hospital Leiden, ${ }^{5}$ Gaubius Institute TNO Leiden, and \\ ${ }^{6}$ Department of Epidemiology, Erasmus University Medical School Rotterdam
}

Received 29 November 1989; accepted for publication 5 April 1990

\begin{abstract}
Summary. We previously reported that mortality due to ischaemic heart disease was lower in haemophilia patients than in the general male population. To support the hypothesis that this could be attributed to a protective effect of the clotting defect in haemophilia and not to differences in cardiovascular risk factors, we performed a second study. We examined 95 haemophilia patients for the presence of major risk factors for ischaemic heart disease and compared their risk factor profile with the data of epidemiologic surveys of the general Dutch population.

Haemophilia patients had on average higher blood pressures than the comparison population, were more often hypertensive and used antihypertensive drugs twice as often.
\end{abstract}

The mean serum cholesterol level of the patients was markedly lower than in the comparison population $(4 \cdot 8$ versus $5.6 \mathrm{mmol} / \mathrm{l}, 95 \%$ confidence interval of the difference: $0 \cdot 5-1 \cdot 1 \mathrm{mmol} / \mathrm{l})$.

The risk factors were weighted into one theoretical risk ratio for ischaemic heart disease by application of logistic regression coefficients. The theoretical risk ratio based on the risk factor profile was $0 \cdot 78$. This risk ratio can only explain a moderate reduction in the incidence of ischaemic heart disease, much smaller than the mortality ratio of 0.20 we reported previously. Therefore these data support the hypothesis of a direct protective effect of haemophilia on the development of ischaemic heart disease.
Recently we reported the results of a follow-up study on mortality in a cohort of 717 patients with haemophilia (Rosendaal et al, 1989). Among a total of 43 deaths, the mortality from ischaemic heart disease was markedly reduced in comparison with the general male population: a mortality ratio of only $0 \cdot 20$, after adjustment for age.

The low mortality of ischaemic heart disease was striking: first, because overall mortality in the cohort was twice as high as expected; second, because it occurred in the face of a high prevalence of hypertension, as judged by the frequent use of antihypertensive drugs by haemophilia patients (Rosendaal et al, 1989). Although this has not been documented, many haematologists feel that haemophilia predisposes to hypertension. A high occurrence of renal disease among haemophiliacs has been reported (Lazerson, 1976; Prentice et al, 1971), which was reflected in our previous

Correspondence: Dr F. R. Rosendaal, Department of Clinical Epidemiology, Building 1, C0-P-46. University Hospital Leiden, P.O. Box 9600, 2300 RC Leiden, The Netherlands. study in a higher than expected mortality from renal insufficiency (Rosendaal et al, 1989).

One is tempted to attribute the low mortality ratio from ischaemic heart disease of $0 \cdot 20$ to the clotting deficiency. This would be justified under two assumptions: first, that the shortfall was not caused by so-called competing risks. A low mortality ratio of ischaemic heart disease could result if other death causes with excess mortality, e.g. stroke, renal failure and cancer, had removed exactly those patients who would otherwise later have died from ischaemic heart disease. Such mechanisms are unlikely, and even if present would also have an effect in the general population with which the mortality was compared, so that this consideration would account for only a very small fraction of the difference in mortality from ischaemic heart disease.

The second assumption one needs to make in order to attribute the low mortality of ischaemic heart disease to the clotting deficiency, is that all other factors relevant to the risk of myocardial infarction were equal among patients and the general population. The present study was conducted to verify this assumption. We examined the classical risk factors 
for ischaemic heart disease, smoking, blood pressure and cholesterol, in haemophilia patients attending the outpatient clinics of two haemophilia centres and compared these to data from two large epidemiologic surveys in the Dutch general population. For each factor the observed risk factor level was compared with the expected risk factor level derived from these surveys. Subsequently, we combined the factors into one overall risk ratio, the 'theoretical risk ratio', based solely on the risk factor profile. This was done by application of logistic coefficients as determined in a study on myocardial infarction in Dutch postal employees (Vandenbroucke \& Matroos, 1981).

In the previous study on mortality in haemophilia (Rosendaal et al, 1989), cancer deaths were conspicuous: 15 deaths from neoplasm occurred while only six were expected. Since six of these were neoplasms of the lung, the question of a higher smoking frequency among haemophilia patients was raised.

\section{METHODS}

All 128 haemophilia patients of the haemophilia centres in Rotterdam and Leiden were invited to participate in this study. For the Leiden centre this also included pediatric patients, while the Rotterdam clinic included only adults. The patients were mailed a small questionnaire that they returned on the day of the examination.

The examination took place in the outpatient clinics of the two centres. The patients were interviewed with regard to smoking habits, chest pain, history of cardiac disease, and use of medical drugs. Blood pressure was measured by one of us (F.R.R.) with a random-zero-sphygmanometer, after the patient had had a minimum of $15 \mathrm{~min}$ of rest. Diastolic pressure was noted as Korotkov's phase 5, which conforms to American Heart Association recommendations (Kirkendall et al, 1981). Blood pressure was taken with the patient in a sitting position, before venopuncture and electrocardiogram (ECG). Hypertension was defined according to the standards of the World Health Organization, at a systolic pressure of $160 \mathrm{mmHg}$ or higher, or a diastolic pressure of $95 \mathrm{mmHg}$ or higher (WHO, 1978). The ECGs were judged by a cardiologist (G.vH.) who was unaware of the patient's medical history. Total cholesterol concentrations were determined by an enzymatic assay (Boehringer Mannheim, F.R.G.), while highdensity lipoproteins (HDL) were measured after sodium phosphate tungstate precipitation as described by LopesVirella et al (1977). In this way both the measurements of blood pressure, with the random-zero-sphygmanometer, and cholesterol were performed in a way identical to that of the population survey to which the results were compared (EPOZ, see below). In this population survey cholesterol levels were also determined by an enzymatic method and in this as well as in our study the World Health Organization standard of the regional lipid reference centre in Prague was used (Valkenburg et al, 1980). Serum creatinine concentrations were measured as a crude index of renal function in the standard fashion. As a measure of relative body weight the Quetelet index was determined (weight (kg)/length $(\mathbf{m})^{2}$ ).

For comparison we used data obtained between 1975 and
1978 in the population based EPOZ study ('Epidemiologic Prevention Study Zoetermeer'), which was carried out in the Dutch town of Zoetermeer, between Leiden and Rotterdam. This study, in which 10532 persons participated, was aimed at obtaining prevalence figures for major chronic diseases and their risk factors. From this study data were available of 5075 men grouped in 5-year age intervals on cholesterol level, blood pressure, Quetelet index and use of antihypertensive medication. As has been described elsewhere, the results of this survey are considered to be representative for the Dutch population (Valkenburg et al, 1980; Hofman \& Valkenburg, 1980, 1983). For comparison of smoking habits between the patients and the general population, information was made available from a large ( $9705 \mathrm{men})$ national survey on smoking that took place in 1988, and earlier surveys from 1972 onwards (Stichting Volksgezondheid en roken, 1988; Central Bureau of Statistics, 1986). We made no distinction between cigarette smoking and other types of tobacco smoking.

Adjustment for age differences between patients and the reference population was performed by standardization with the age distribution of the patients as weights. This led to the calculation of an expected risk factor profile, i.e. that one would encounter in a group of men from the general population with the same age distribution as the patients. The standard error of the standardized values was obtained by calculation of a weighted average of the standard errors in each 5-year age group with the squared size of the age groups in the patient population as weights. The standard error of each risk factor in the patients and the standard error of the standardized expected risk factor value were pooled to obtain a $95 \%$ confidence interval of the risk factor difference.

We then calculated the odds ratio for ischaemic heart disease of patients in comparison with the reference population combining the factors smoking, cholesterol, systolic blood pressure and Quetelet-index. This odds ratio estimates the theoretical risk ratio for myocardial infarction, given the levels of the risk factors we studied. We weighted the values of these factors by application of the coefficients of a logistic regression model of a study on first myocardial infarction of Dutch postal employees (Vandenbroucke \& Matroos, 1981). The coefficients reported from this study for systolic blood pressure $(0.0155 \mathrm{mmHg})$, cholesterol $(0.011 \mathrm{mg} / \mathrm{dl}$, i.e. $0.4231 \mathrm{mmol} / \mathrm{l})$ and Quetelet-index $\left(0.0052 \mathrm{~kg} / \mathrm{m}^{2}\right)$ were almost identical to those found in the Framingham Heart study (Truett et al, 1967). The Dutch study discriminated between smokers and non-smokers (coefficient 0.8510), while in the report from the Framingham study coefficients were given for medium and heavy smoking.

The study on Dutch postal employees from which the logistic coefficients were derived, included only individuals of 40 years and older, i.e. on average older than the haemophilia patients and the EPOZ reference population. One might question the use of logistic coefficients derived from an older group, even when adjustment has been performed for the age difference between the haemophilia patients and the EPOZ reference population. Therefore, we provide a separate analysis limited to the patients aged 40 years and older.

In the logistic model the logarithm of the odds on disease 
Table I. Observed and expected risk factor profile

\begin{tabular}{|c|c|c|c|c|}
\hline \multirow[b]{2}{*}{ Factor } & \multicolumn{2}{|c|}{ Observed } & \multicolumn{2}{|c|}{ Expected } \\
\hline & Mean & C195 & Mean & CI95 \\
\hline $\begin{array}{l}\text { Systolic pressure } \\
(\mathrm{mmHg})\end{array}$ & 133 & $129-137$ & 129 & $129-130$ \\
\hline $\begin{array}{l}\text { Diastolic pressure } \\
(\mathrm{mmHg})\end{array}$ & 82 & $80-85$ & 77 & $76-77$ \\
\hline $\begin{array}{l}\text { Total cholesterol } \\
(\mathrm{mmol} / \mathrm{l})\end{array}$ & $4 \cdot 8$ & $4 \cdot 5-5 \cdot 0$ & $5 \cdot 6$ & $5 \cdot 5-5 \cdot 6$ \\
\hline Smokers (\%) & 44 & $34-54$ & 41 & $40-42$ \\
\hline Quetelet index $\left(\mathrm{kg} / \mathrm{m}^{2}\right)$ & $22 \cdot 8$ & $22 \cdot 0-23 \cdot 7$ & $23 \cdot 2$ & $23 \cdot 2-23 \cdot 3$ \\
\hline
\end{tabular}

Under 'observed' the risk factor profile of the patients is shown, with a $95 \%$ confidence interval (CI95) of the mean of each factor. Under 'expected' the risk factor profile of the comparison population is given, standardized for age differences. For the patients all factors refer to 95 patients, except for the figures on smoking which refer to 87 patients aged 15 years and older. The expected values refer to 4974 men for blood pressure, 4913 men for cholesterol, 9705 men (aged 15 years and older) for smoking and 4929 men for Quetelet indices.

is written as a linear function of the factors, $\ln$ (odds) $=$ $\alpha+\Sigma\left(\beta_{i} x_{i}\right)$, in which $x_{i}$ are the values of the risk factors and $\beta_{i}$ the corresponding coefficients. The odds ratio on myocardial infarction for patients $(\mathrm{P})$ in comparison with the reference population (R) becomes the antilog of $\Sigma \beta_{i}\left(x_{1, \mathrm{P}}-x_{1, \mathrm{R}}\right)$.

In this analysis the coefficients are applied to the standardized average risk factor values in patients and reference population. Two populations with the same average value, however, could have very different risks if the distribution of risk factor levels differed widely, because of the exponential relation of risk and risk factor. For instance, if in population $\mathrm{A}$ all individuals had a cholesterol level of $5.0 \mathrm{mmol} / \mathrm{l}$ and in population $B$ half of the individuals had levels of $2.0 \mathrm{mmol} / \mathrm{l}$ and the other half of $8.0 \mathrm{mmol} / \mathrm{l}$, average levels would be equal. Nevertheless, the risk in population $B$ would be almost double to that of population $A$. We compared the distribution of the risk factors in the patients and the reference population by the variance ratio (patients over reference population. overall variance), which was $1 \cdot 04$ for systolic blood pressure, 1.32 for cholesterol levels, and 0.92 for Quetelet index; none of these, as tested by the F-distribution differed significantly $(P$-value $<0 \cdot 05)$ from a variance ratio of $1 \cdot 0$.

\section{RESULTS}

Ninety-five out of 128 patients (74\%), 48 in Leiden and 47 in Rotterdam, agreed to participate in the study. Eighty-seven (92\%) of the 95 patients had haemophilia $A$, eight had haemophilia B. Thirty-three (35\%) had severe haemophilia (less than 1\% clotting factor activity), 15 (16\%) had moderately severe haemophilia ( $1-5 \%$ activity) and 47 (49\%) had a mild form (more than $5 \%$ activity). Their age ranged from 7 to 76 years (mean age 38 years). This age distribution did not differ much from that of the EPOZ reference population, in which the mean age was 32 years.
Table II. Theoretical odds risk ratio of myocardial disease

\begin{tabular}{|c|c|c|c|}
\hline Factor (i) & $\begin{array}{l}\text { Difference } \\
x_{1, P}-x_{1 \mathrm{R}}\end{array}$ & CI95 & $\begin{array}{l}\text { Coefficient } \\
\beta_{l}\end{array}$ \\
\hline Systolic pressure (mmHg) & $3 \cdot 7$ & $-0 \cdot 3-7 \cdot 7$ & 0.0155 \\
\hline Diastolic pressure (mmHg) & $5 \cdot 8$ & $3 \cdot 6-8 \cdot 0$ & \\
\hline Total cholesterol $(\mathrm{mmol} / \mathrm{l})$ & -0.8 & $-1 \cdot 1--0 \cdot 5$ & 0.4231 \\
\hline Smokers (\%) & 3 & $-7-12$ & 0.00851 \\
\hline Quetelet index $\left(\mathrm{kg} / \mathrm{m}^{2}\right)$ & -0.4 & $-1 \cdot 3-0 \cdot 4$ & 0.0052 \\
\hline
\end{tabular}

The difference is the observed risk factor level of the patients $(\mathrm{P})$ minus the expected level of the reference population (R). The $95 \%$ confidence interval of the difference (C195) is based on the pooled standard error of the patient group's standard error and the error of the standardized expected factor level which, since the latter standard errors were very small, is almost identical to the patient factor standard errors alone.

Table I shows the observed risk factor values in the patients and the expected risk factor values from the comparison population. Both the systolic and diastolic blood pressures were higher among the patients than in the comparison population. Total cholesterol levels were lower, while the Quetelet indices and the percentage of smokers were about equal. The application of the coefficients of the logistic model for these four factors led to a theoretical odds risk ratio for ischaemic heart disease of patients over comparison population of 0.78 (Table II). This means that, based solely on the risk factor profile, the patients' odds for myocardial infarction were $22 \%$ lower than in the comparison population. When the analysis was limited to the 42 patients aged 40 years and older, and expected risk factor levels were calculated for this group, application of the logistic coefficients resulted in a very similar odds ratio of $0 \cdot 80$.

In addition to the higher mean blood pressure levels among the patients, the use of antihypertensive drugs was more common among the patients. Among the 5075 men of the EPOZ reference population $4 \cdot 1 \%$ used antihypertensive drugs, while $11.6 \%(11 / 95)$ of the patients were treated with these drugs. After age adjustment (by weighting to the age distribution of the patients) the observed frequency of use of antihypertensive agents was still $2 \cdot 3$ times as high as the expected frequency. If we consider hypertensive those individuals who either have blood pressures exceeding $160 \mathrm{mmHg}$ systolic or $95 \mathrm{mmHg}$ diastolic, or receive antihypertensive drug treatment, patients were 1.9 times as often hypertensive as the comparison population (after age-standardization). To verify whether patients were treated with antihypertensive drugs at lower blood pressures than the reference population, we compared the individuals who were not treated with antihypertensive drugs. Among these, the patients were 1.5 times as often hypertensive as the reference population (systolic pressure over $160 \mathrm{mmHg}$ or diastolic over $95 \mathrm{mmHg}$ ). Taken together, these findings support the clinical impression that hypertension is common among haemophilia patients. We could not observe any relation 


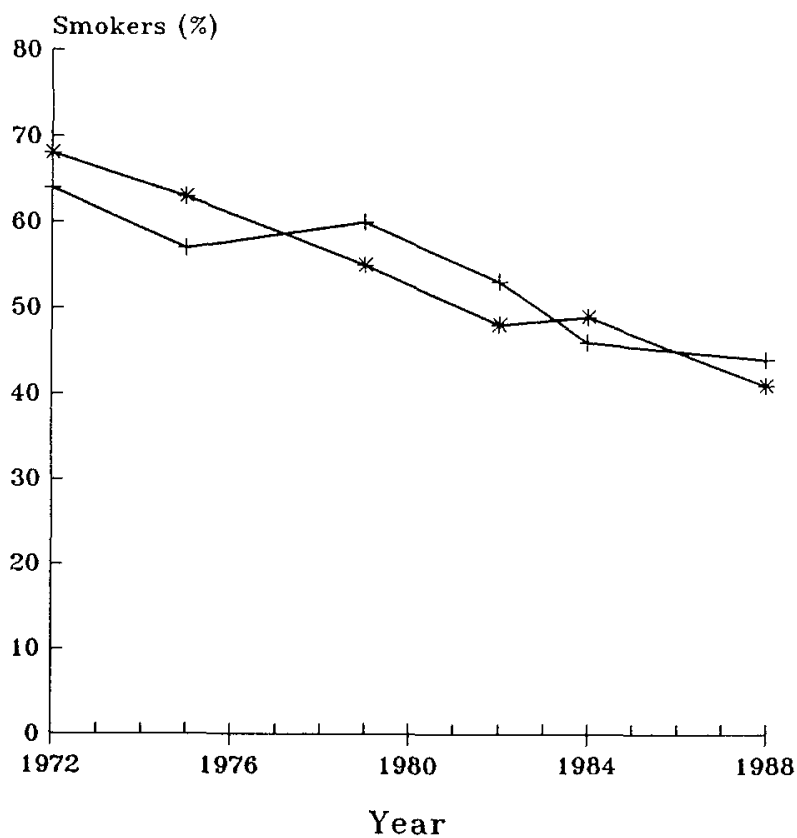

Fig 1. Percentage smokers from 1972 to 1988. Patients: + population: *. The percentage of smokers of the patients is adjusted for age by standardization. The data for 1972, 1975, 1979, 1982 and 1984 compare individuals from 13 years and older. They refer to surveys of the Dutch population numbering $12191,4607,4454$, 3398 and 3324 males, respectively (Central Bureau of Statistics, 1986). The data of 1988 were compared to the NIPO-survey, numbering 9705 males (Stichting Volksgezondheid en Roken, in The Hague, unpublished observation).

between severity of haemophilia and hypertension. The prevalence of hypertension among the patients was strongly associated with age: up to 24 years of age none were hypertensive, between 25 and 49 years of age $7 / 45$ were hypertensive $(16 \%)$ and among those aged 50 or more $15 / 26$ (58\%).

Since a high occurrence of renal disease among haemophilia patients has been reported (Lazerson, 1976; Prentice et al, 1971) as well as an increased mortality due to renal insufficiency (Rosendaal et al, 1989), we measured plasma creatinine levels as a crude index of renal function to see if this was related to the occurrence of hypertension. After adjusting for age by logistic regression on hypertension. defined as either hypertensive blood pressure or use of antihypertensives, creatinine levels did not prove to be associated with the occurrence of hypertension (quartiles of creatinine levels, $\beta=0 \cdot 05, \mathrm{OR}=1 \cdot 05$ ).

$44 \%$ of the patients $(38 / 87$ patients aged 15 years and older) were current smokers, as compared to $41 \%$ in the comparison population.

Since information on beginning and giving up smoking was available, we could compare the percentage of smokers within the patient group from 1972 to the present with the Dutch male population. From Fig 1 there appears to be no difference between the smoking habits in both groups.

The haemophilia patients had markedly lower levels of serum cholesterol than the comparison population. The mean serum cholesterol concentration was $3.8 \mathrm{mmol} / \mathrm{l}$ in the patients younger than 25 years, $4.8 \mathrm{mmol} / \mathrm{l}$ in those aged $25-49,5 \cdot 2 \mathrm{mmol} / \mathrm{l}$ for the ages $50-64$ and $6 \cdot 2 \mathrm{mmol} / \mathrm{l}$ in the patients aged 65 and older. The patients with severe haemophilia had on average the lowest cholesterol levels. For severe haemophilia the mean cholesterol level was $4.4 \mathrm{mmol} / \mathrm{l}$, for moderately severe haemophilia it was $4.7 \mathrm{mmol} / \mathrm{l}$ and for mild haemophilia $5.0 \mathrm{mmol} / \mathrm{l}$. The concentration of HDL cholesterol was $1.0 \mathrm{mmol} / \mathrm{l}$ on average, and did not differ by age or severity of haemophilia. When we performed linear regression with age and severity as independent variables on total cholesterol concentration, patients with more severe forms of haemophilia still had the lowest cholesterol levels, although the $95 \%$ confidence interval of the regression coefficient included zero.

No data on the Dutch population were available to compare the HDL cholesterol. The mean level of $1.0 \mathrm{mmol} / \mathrm{l}$ is lower than that reported in studies from the United States. In one study on 2568 men an average HDL cholesterol level of $1.4 \mathrm{mmol} / \mathrm{l}$ was reported (Williams et al, 1979), while in the Framingham study the median HDL cholesterol level for $1189 \mathrm{men}$ was $1 \cdot 14 \mathrm{mmol} / \mathrm{l}$ (Wilson et al, 1988). This latter figure was deduced from the range of the third quintile, the mean value will in fact be even higher because of the right skewed distribution.

Another approach to the question of a protective effect of haemophilia against the development of myocardial infarction, was to look for evidence of ischaemic heart disease among these 95 patients. This was examined both by an interview for anginal complaints and a resting electrocardiogram. None of the patients had a history of myocardial infarction. One 44-year-old patient with mild haemophilia A reported typical exercise related angina. None of the electrocardiograms provided evidence for old myocardial infarctions, although one was considered suspect. This 61 -year-old patient with mild haemophilia A did not report any history of chest discomfort. Since no information on the prevalence of ischaemic abnormalities was available for the general population, these data could not be compared to an expected figure.

\section{DISCUSSION}

The theoretical mortality ratio for myocardial infarction of $0 \cdot 78$, based solely on the risk factor profile, cannot explain the observed mortality ratio of $0 \cdot 20$ (Rosendaal et al, 1989). Therefore we conclude that haemophilia may offer direct protection against myocardial infarction.

The risk odds ratio of $0 \cdot 78$, which predicts a theoretical $22 \%$ lowering of the risk of myocardial infarctions because of the risk factor profile, might even be closer to 1 , since many patients received antihypertensive treatment. Clinical trials have shown that pharmaceutical treatment of hypertension is far more effective in preventing peripheral organ damage than coronary artery disease (Veterans Administration Cooperative Study Group on Antihypertensive Agents, 1970; Strate et al, 1986). It seems likely that treatment does not reduce the risk of myocardial infarction to the figure of normotensive individuals, even when normal blood pres- 
sures are reached. This implies that the risk factor profile of the patients would differ even less from that of the comparison population.

The comparability of the risk factor profiles of the patients and the population of the epidemiologic surveys has to be addressed. Since the patients were living in the geographical area where the EPOZ study was performed, we have little doubt that this was the right reference group for comparison. The figures on smoking were compared to a very large survey performed in the year preceding our study and therefore the comparison may be considered fair. One might question, however, whether any major changes occurred in the general population or in laboratory methods during the 10-year interval between the EPOZ study and ours. Health education may have lowered cholesterol levels because of dietary measures. It is unlikely, however, that this would account for a $0.8 \mathrm{mmol} / \mathrm{l}$ difference. In both studies, cholesterol determinations were standardized to the same reference centre, and therefore differences between laboratories or secular changes in laboratory methods cannot explain the difference.

Blood pressures are also not very likely to have changed with time, while the consumption of antihypertensive drugs in The Netherlands has remained fairly constant (Institute for Medical Statistics, 1988). The overall mortality of ischaemic heart disease in the Dutch male population has decreased by $15 \%$ since the 1970 s [from 214 in 1975 to 182 in 1984, per million, standardized to the population of 1960 (Central Bureau of Statistics, 1986)]. This decrease coincided with a reduction in the number of smokers from $63 \%$ in 1975 to $49 \%$ in 1984 (Central Bureau of Statistics, 1986). These figures indicate that no major changes in the risk factors other than smoking have occurred in the general population between the time of the epidemiologic surveys and our study that might have rendered the comparison unjustified.

Our findings confirm the impression that haemophilia patients are often hypertensive. It could be argued that the close medical care received by haemophilia patients makes it more likely that hypertension is detected and subsequently treated. This, however, appeared not to be an explanation for the high frequency of hypertension among haemophilia patients, since the mean blood pressures were also higher than expected in the patients not treated for hypertension. Moreover, even though antihypertensive treatment was more than twice as common as in the comparison population, the overall mean blood pressures were still higher than expected.

An unexpected finding in this study was the marked difference in cholesterol levels between the patients and the comparison group. It seems plausible that the low cholesterol levels we observed were associated either with the clotting defect or with its treatment, since they were lowest in the patients with severe haemophilia. Patients with haemophilia are during their lifetime heavily exposed to foreign proteins, which affect the immune system as well as liver function, because of viral infections. These alterations caused by treatment with preparations from human plasma might offer an explanation for the low cholesterol levels. Low cholesterol concentrations have been associated with an increased cancer incidence in several large studies (Rose et al, 1974; Morris et al, 1983; International Collaborative Group, 1982). In our follow-up study on mortality we also observed a high cancer mortality in haemophilia patients (Rosendaal et al. 1989). It is a matter of some debate whether the observations associating low cholesterol levels with an increased cancer risk represent a true effect of low cholesterol (McMichael $e t$ al, 1984). Recent reports show that the effect can only be observed in the first few years of follow-up, which makes it most likely that the association is caused by preclinical cancers lowering cholesterol (Sherwin et al, 1987; Knekt et al. 1988).

A large proportion of the excess cancer deaths we reported in our previous paper was caused by cancers of the lung (Rosendaal et al, 1989). One of the possible explanations offered was a preponderance of smokers among haemophilia patients. Other hypotheses were an effect inherent to the clotting deficiency itself or its treatment and in particular the immune alterations caused by replacement therapy (Brettler et al, 1986; Madhok et al, 1986). When current smoking and past smoking were taken together, no preponderance of smokers among haemophilia patients emerged.

Myocardial infarction is the result of many years of atherosclerotic coronary disease followed by coronary thrombosis (DeWood et al, 1980). A protective effect of low clotting factor levels has been shown for fibrinogen (Wilhelmsen $e$ al, 1984; Kannel $e t$ al, 1987) and factor VII (Meade et al, 1986). It can be deduced from the report of the Northwick Park study (Meade et al, 1986) that individuals in the general population in the highest tertile of factor VIII levels had a $40 \%$ higher risk of myocardial infarction than those in the lowest tertile. This association was reported to be non-significant $(P=0 \cdot 2)$. It has to be borne in mind, however, that the factor VIII levels are far lower in haemophilia patients than in the non-haemophilic population of the Northwick Park study. Taken together these data suggest that also in the nonhaemophilic population low factor VIII levels have a protective effect. It remains unresolved whether the protective effect only applies to the final thrombotic event, or also to the atherosclerotic process itself. It may well be possible that clotting factor activity is a necessary or promoting factor in the formation of atherosclerotic plaques. The finding of a protective effect of a clotting deficiency is in accordance with the reports of a beneficial effect of oral anticoagulants in the prevention of recurrent myocardial infarction (Sixty-plus Reinfarction Study Research Group, 1980; Smith et al, 1989), although this effect has been the subject of an interminable and never settled dispute since it was first postulated.

\section{ACKNOWLEDGMENTS}

We thank the patients who so generously cooperated in our study. The staff and nurses of both haemophilia units are thanked for their practical assistance and their kind hospitality. Mrs J. Siebel and Mrs W. Noteboom gave technical assistance for which we are indebted to them. We are grateful to Dr J. Souverijn, Central Laboratories for Clinical Chemistry of the Academic Hospital Leiden and to H. A. van der Voort, 
Gaubius Institute TNO, for the laboratory tests. Dr A. Hoes of the Department of Epidemiology, Erasmus University Medical School Rotterdam, assisted in making the EPOZ data available to us. The Stichting Volksgezondheid en Roken kindly supplied the results of the latest survey on smoking.

\section{REFERENCES}

Brettler, D.B., Forsberg, A.D., Brewster, F., Sullivan, J.L. \& Levine, P.H. (1986) Delayed cutaneous hypersensitivity reactions in hemophiliac subjects treated with factor concentrate. American Journal of Medicine, 81, 607-611.

Central Bureau of Statistics (1986) Compendium of health statistics of the Netherlands 1986. Ministry of Welfare. Health and Cultural Affairs, Staatsuitgeverij, The Hague.

DeWood, M.A., Spores, J., Notske, R., Mouser, L.T., Burroughs, R., Golden, M.S. \& Lang, H.T. (1980) Prevalence of total coronary occlusion during the early hours of transmural myocardial infarction. New England Journal of Medicine, 303, 897-902.

Hofman, A. \& Valkenburg, H.A. (1980) Een epidemiologisch onderzoek naar risico-indicatoren voor hart-en vaatziekten (EPOZ). II. Voorkomen, opsporing en behandeling van hypertensie in een open bevolking. Nederlands Tijdschrift voor Geneeskunde, 124, 189-195.

Hofman, A. \& Valkenburg, H.A. (1983) Determinants of blood pressure in childhood. American Journal of Epidemiology. 117, 735-743.

Institute for Medical Statistics (IMS) (1988) Diagnose Informatie en Medische Statistiek, 4: Hypertensie. Institute for Medical Statistics, The Hague.

International Collaborative Group (1982) Circulating cholesterol level and risk of death from cancer in men aged 40 to 69 years. Journal of the American Medical Association, 248, 2853-2859.

Kannel, W.B., D'Agostino, R.B. \& Belanger, A.J. (1987) Fibrinogen, cigarette smoking and risk of cardiovascular disease: Insights from the Framingham study. American Heart Journal, 113, 1006-1010.

Kirkendall, W.M., Feinleib, M., Fries, E.D. \& Mark, A.L. (1981) Recommendations for human blood pressure determination by sphygmanometers (AHA Committee Report). Hypertension, 3, 509A-519A.

Knekt, P., Reuanen, A., Aromaa, A., Heliövaara, M., Hakulinen, T. \& Hakama, M. (1988) Serum cholesterol and risk of cancer in a cohort of 39000 men and women. Journal of Clinical Epidemiology, 41, 519-530.

Lazerson, J. (1976) Renal disease in hemophilia. Hemophilia in Children (ed. by M. W. Hilgartner), pp. 71-78. Acton Mass Publishing Sciences Group, Acton.

Lopes-Virella, M.F., Stone, P., Ellis, S. \& Colwell, J.A. (1977) Cholesterol determination in high-density lipoproteins separated by three different methods. Clinical Chemistry, 23, 882-884.

Madhok, R., Gracie, A., Lowe, G.D.O., Burnett, A., Froebel, K., Follett, E. \& Forbes, C.D. (1986) Impaired cell mediated immunity in haemophilia in the absence of infection with human immunodeficiency virus. British Medical Journal, 293, 978-980.

McMichael, A.J., Jensen, O.M., Parkin, D.M. \& Zaridze, D.G. (1984) Dietary and endogenous cholesterol and human cancer. Epidemiologic Reviews, 6, 192-217.

Meade, T.W., Mellows, S., Brozowic, M., Miller, G.J., Chakrabarti, R.R., North, W.R.S., Haines, A.P., Stirling, Y., Imeson, J.D. \& Thompson, S.G. (1986) Haemostatic function and ischaemic heart disease: principal results of the Northwick Park study. Lancet, ii, 533-537.
Morris, D.L., Borhani, N.O., Fitzsimons, E., Hardy, R.J., Hawkins, C.M., Kraus, J.F., Labarthe, D.R., Mastbaum, L. \& Payne, G.H. (1983) Serum cholesterol and cancer in the Hypertension Detection and Follow-up Program. Cancer, 52, 1754-1759.

Prentice, C.R.M., Lindsay, R.M., Barr. R.D., Forbes, C.D., Kennedy. A.C., McNicol, G.P. \& Douglas, A.S. (1971) Renal complications in haemophilia and Christmas disease. Quarterly Journal of Medicine. 157, 47-61.

Rose, G., Blackburn, H., Keys, A., Taylor, H.L., Kannel, W.B., Paul, O., Reid, D.D. \& Stamler, J. (1974) Colon cancer and blood cholesterol. Lancet, i, 181-183.

Rosendaal, F.R., Varekamp, I., Smit, C., Bröcker-Vriends, A.H.J.T., Van Dijck, H., Vandenbroucke, J.P., Hermans, J., Suurmeijer, T.P.B.M. \& Briët, E. (1989) Mortality and causes of death in Dutch haemophiliacs, 1973-1986. British Journal of Haematology, 71, 71-76.

Sherwin, R.W., Wentworth. D.N., Cutler, J.A., Hulley, S.B., Kuller. L.H. \& Stamler, J. (1987) Serum cholesterol levels and cancer mortality in 361662 men screened for the Multiple Risk Factor Intervention Trial. Journal of the American Medical Association, 257, 943-948.

Sixty-plus Reinfarction Study Research Group (1980) Report of the sixty-plus reinfarction study research group: a double blind trial to assess long-term oral anti-coagulant therapy in elderly patients after myocardial infarction. Lancet, ii, 989-994.

Smith, P., Arnesen, H. \& Holme. I. (1989) Effects of oral anticoagulants on mortality, recurrent infarction and cerebrovascular attacks in survivors of acute myocardial infarction. (Abstract). Thrombosis and Haemostasis (Suppl.), 62, 327.

Stichting Volksgezondheid en Roken (1988) NIPO-enquete 1988 (Unpublished data).

Strate, M., Thygesen, K., Ringsted, C., Hansen, L. \& Harvald, B. (1986) Prognosis in treated hypertension. Acta Medica Scandinavica, 219, 153-159.

Truett, J., Cornfield, J. \& Kannel, W. (1967) A multivariate analysis of the risk of coronary disease in Framingham. Journal of Chronic Disease, 20, 511-524.

Valkenburg, H.A., Hofman, A., Klein, F. \& Groustra, F.N. (1980) Een epidemiologisch onderzoek naar risico-indicatoren voor hart-en vaatziekten (EPOZ). I. Bloeddruk, serumcholesterolgehalte, Quetelet-index en rookgewoonten in een open bevolking van vijf jaar en ouder. Nederlands Tijdschrift voor Geneeskunde, 124, 183-189.

Vandenbroucke, J.P. \& Matroos, A. (1981) Een gedeeltelijke risicofunctie voor myocardinfarct, berekend op grond van een Nederlands 'case-referent' onderzoek. Nederlands Tijdschrift voor Geneeskunde, 125, 1873-1877.

Veterans Administration Cooperative Study Group on Antihypertensive Agents (1970) Effects of treatment on morbidity in hypertension: II. Results in patients with diastolic blood pressures averaging 90 through $114 \mathrm{mmHg}$. Journal of the American Medical Association, 213, 1143-1152.

Wilhelmsen, L., Svärsudd, K., Korsan-Bengtsen, K., Larsson. B., Welin, L. \& Tibblin, G. (1984) Fibrinogen as a risk factor for stroke and myocardial infarction. New England Journal of Medicine. 311 , 501-505.

Williams, P., Robinson, D. \& Bailey, A. (1979) High-density lipoprotein and coronary risk factors in normal men. Lancet, i, 72-75.

Wilson, P.W.F., Abbott, R.D. \& Castelli, W.P. (1988) High density lipoprotein cholesterol and mortality: the Framingham heart study. Arteriosclerosis, 8, 737-741.

World Health Organization (1978) Arterial hypertension report of the WHO expert committee. World Health Organization, 1978; technical report series no. 628 . 